\title{
Heat transfer modeling in asymmetrical sheet rolling of aluminium alloys with ultra high shear strain
}

\author{
Alexander Pesin ${ }^{a}$, Denis Pustovoytov \\ Nosov Magnitogorsk State Technical University, Department of Material processing, 455000, Magnitogorsk, Lenin prospect, 38, Russia
}

\begin{abstract}
Asymmetrical sheet rolling is a method of severe plastic deformation (SPD) for production of aluminium alloys with UFG structure. Prediction of sheet temperature during SPD is important. The temperature of sheet is changed due to the conversion of mechanical work into heat through sliding on contact surfaces and high shear strain. Paper presents the results of FEM simulation of the effect of contact friction, rolling speed and rolls speed ratio on the heating of aluminium sheets during asymmetrical rolling.
\end{abstract}

\section{Introduction}

The aluminium alloys have been used extensively in aerospace and automobile industries because of their low density and high specific strength [1]. Conventional strengthening mechanisms applicable to aluminium alloys like solid solution strengthening, work hardening and precipitation hardening have their own limitations [2]. Although these mechanisms cause considerable strengthening, they cannot improve the properties to match steel. Hence, the need arises for novel processing methods and new techniques to improve properties of aluminium alloys. A possible way to further increase strength of aluminium alloys is to form an ultrafine grain (UFG) structure using severe plastic deformation (SPD) methods [3]. Nowadays many variants of SPD techniques are available [4]. Asymmetric rolling process is one of them [5-8]. Contrary to other SPD methods such as high pressure torsion and equal channel angular pressing, the asymmetric rolling allows to provide the possibility for overcoming the limitation of producing ultrafine grained materials with large dimensions due to its continuous feature. Among the asymmetric rolling processes, the differential speed rolling in which the speeds of the upper and lower rolls are different, is considered to be the most effective for achieving ultrafine grained structure of aluminium alloys [9-10].

It is well known that shear strain plays a critical role in the grain refinement of aluminium alloys processed by asymmetric rolling [11-15]. The strength of the material continuously increases with increasing the applied shear strain. However the resulting plastic work is converted into heat energy. Therefore it is necessary to estimate the actual sheet temperature during the asymmetric rolling for a precise control of recovery/recrystallization, and hence of the grain size.

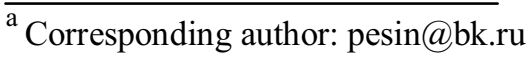

Many works studied the shear strain during asymmetric rolling by using finite element method (FEM). Ji and Park [16] analysed various asymmetric rolling processes by the rigid-viscoplastic FEM. The results of the numerical simulation demonstrated that shear strain is more severe in the material layers, where the circumferential speed or friction coefficient is greater. Ji et al. [17] investigated the deformation mechanics of differential speed rolling with a high-speed ratio between the rolls by rigid-plastic FEM. It was found out that the shear strain takes a great portion of the total effective strain in average. Kim et al. [18] analysed the effect of speed ratio on the development of shear strain and texture during differential speed rolling. FEM simulation results showed that the effective strain accumulated during asymmetric rolling increased with high-speed ratio. It was demonstrated that high-ratio differential speed rolling, where a large shear strain is induced during asymmetric rolling at high speed ratios of $\geq 2$, is quite effective for grain refinement. FE analysis of SPD in differential speed rolling was studied in [19]. Effects of the speed ratio, the friction coefficient and the length of deformation zone were investigated by the rigid-plastic finite-element analysis. As a result, mechanisms in development of plastic deformation and an upper limit of the speed ratio were found. Double-pass differential speed rolling was introduced to achieve the symmetric distribution of the effective strain through thickness of the sheet. It was shown that an excessive speed ratio unnecessarily wastes a portion of the power through friction at the interface between the sheet and rolls. This also exerts a tensile stress in the sheet, which could result in fracture.

Influence of process parameters on distribution of shear strain through sheet thickness during asymmetric rolling was investigated by FEM in [20]. It was found that shear strain strongly depends on opposite contact 
friction forces operated in the deformation zone. Ultra high shear strain through the sheet thickness can be obtained with the following parameters: 1) high thickness reduction per pass $(\geq 50 \%) ; 2)$ rolls speed ratio $(\geq 2)$ should be equal to thickness reduction per pass; 3) friction coefficient must be very high, so the asymmetric rolling must be carried out without lubrication. The problem with dry cold asymmetric rolling is the high heat generated in the roll gap by contact friction and the plastic deformation of the aluminium alloys. The heat generation is usually around $90-95 \%$ of the mechanical work. The temperature rise during the asymmetric rolling can be as large as to increase the workpiece temperature above the recovery temperature or the grain growth temperature. Therefore by creating the UFG structure in aluminium alloys it is important to know the value of deformation heat because of recovering processes which are activated at particular temperature level.

The temperature rise during cold asymmetric rolling depends on the thickness reduction per pass, the friction coefficient, rolling speed and rolls speed ratio. Therefore the asymmetric rolling with high-speed ratio and high contact friction is a process that may be limited by temperature rise of the rolled aluminium sheets. There are many publications on the deformation behaviour during asymmetric rolling by using FEM. However, only a few activities on the analysis of temperature and heat transfer have been reported [21-22]. In the present study, finite element simulation was conducted to analyse the heat transfer and temperature field of the sheet during cold asymmetric rolling of aluminium alloys. In order to better understand both temperature distribution and strain characteristics during the processing of aluminium alloys, FEM simulations were carried out for asymmetric rolling at room temperature under different rolling parameters. The heat transfer analysis presented in this study can be used to optimize the asymmetric rolling process as SPD method to improve microstructure and mechanical properties of aluminium sheets.

\section{Research method}

A coupled deformation and heat transfer simulation of the asymmetric rolling was carried out using the commercial FEM code DEFORM 3D. FEM simulation leads to reduction of costs in comparison with physical modeling. The geometry model and FE meshing of asymmetric rolling process is shown in Fig. 1. Process simulation was performed at room temperature with taking into account the increment of the metal's temperature due to the conversion of mechanical work into heat.

The governing equation for heat transfer is expressed as $[23,24]$ :

$$
\mathrm{k} \nabla^{2} \mathrm{~T}+\dot{\mathrm{q}}=\rho \mathrm{C} \frac{\partial \mathrm{T}}{\partial \mathrm{t}}
$$

where $\rho$ is the density, $\mathrm{C}$ is the specific heat capacity, $\mathrm{T}$ is the temperature, $\mathrm{t}$ is time, $\mathrm{k}$ is the thermal conductivity, and $\dot{q}$ is a heat generation term.
Heat generation in asymmetrical rolling is due to work of plastic deformation and friction. Heat generation due to plastic deformation is given by $[23,24]$ :

$$
\dot{\mathrm{q}}_{\mathrm{pw}}=\xi \int \bar{\sigma} \dot{\bar{\varepsilon}} \mathrm{dV}
$$

where $\xi$ is a deformation efficiency term, representing the fraction of the work of deformation converted to heat and is assumed as $0.9, \bar{\sigma}$ is the flow stress, $\dot{\bar{\varepsilon}}$ is strain rate.

The boundary condition for the roll-sheet contact surface includes friction heating and heat exchange via temperature difference of two objects [23, 24]:

$$
\dot{\mathrm{q}}_{1}=\int_{\mathrm{S}_{1}} \eta \mathrm{f}_{\mathrm{S}_{1}}\left|\mathrm{u}_{\mathrm{S}_{1}}\right| \mathrm{dS}_{1}+\int_{\mathrm{S}_{1}} \mathrm{H} \Delta \mathrm{TdS}_{1}
$$

where $u_{S_{1}}$ is the sliding velocity, $f_{S_{1}}$ is the friction stress, $\eta$ is the fraction of friction energy absorbed by the object and is assumed as $0.9, \mathrm{H}$ is the lubricant heat transfer coefficient, and $\Delta \mathrm{T}$ is the temperature difference between two objects.

The boundary condition of the free surface includes convection heat and radiation heat from/to the environment $[23,24]$ :

$$
\dot{\mathrm{q}}_{2}=\int_{\mathrm{S}_{2}} \mathrm{~h}_{\mathrm{c}}\left(\mathrm{T}-\mathrm{T}_{\infty}\right) \mathrm{dS}_{2}+\int_{\mathrm{S}_{2}} \sigma \varepsilon\left(\mathrm{T}^{4}-\mathrm{T}_{\infty}^{4}\right) \mathrm{dS}_{2}
$$

where $h_{c}$ is the convection heat transfer coefficient, $T_{\infty}$ is the environment temperature, $\sigma$ is the StefanBoltzmann radiation constant, and $\varepsilon$ is the emissivity of the surface.

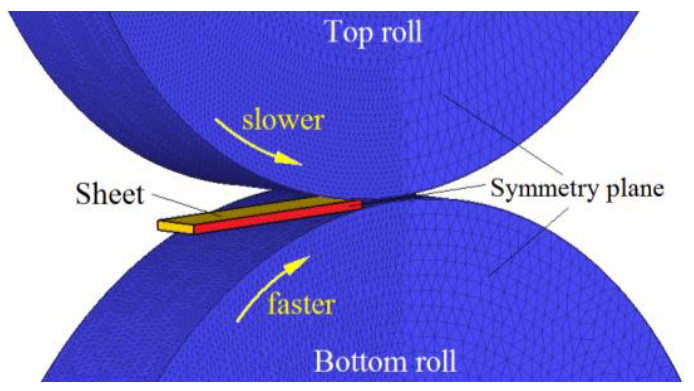

Figure 1. Geometry model and FE meshing of asymmetric rolling process

Pure aluminium $\left(20-250^{\circ} \mathrm{C}, 1-100 \mathrm{~s}^{-1}\right)$, aluminium alloys Al $5083\left(20-440^{\circ} \mathrm{C}, 1-100 \mathrm{~s}^{-1}\right)$ and $\mathrm{Al} 7075$ (20$440^{\circ} \mathrm{C}, 1-100 \mathrm{~s}^{-1}$ ) from DEFORM 3D material library were chosen as a hardened rigid-plastic materials for the sheet. As an example, the stress-strain curves of the materials at $20^{\circ} \mathrm{C}$ and strain rate $1.0 \mathrm{~s}^{-1}$ are shown in Fig. 2.

The thermal constants of pure $\mathrm{Al}$ and its alloys Al 5083 and Al 7075 used in FEM simulation are shown in Table 1. The diameters of the rolls were $200 \mathrm{~mm}$, and the rolls were considered as rigid. High-carbon chromium alloy steel AISI D2 from DEFORM 3D material library was chosen as a material for rolls. The simulations were carried out at three different heat transfer coefficients $\mathrm{H}$ between rolls and sheet (Table 1). Thermal properties were taken as constants to improve computational efficiency. 


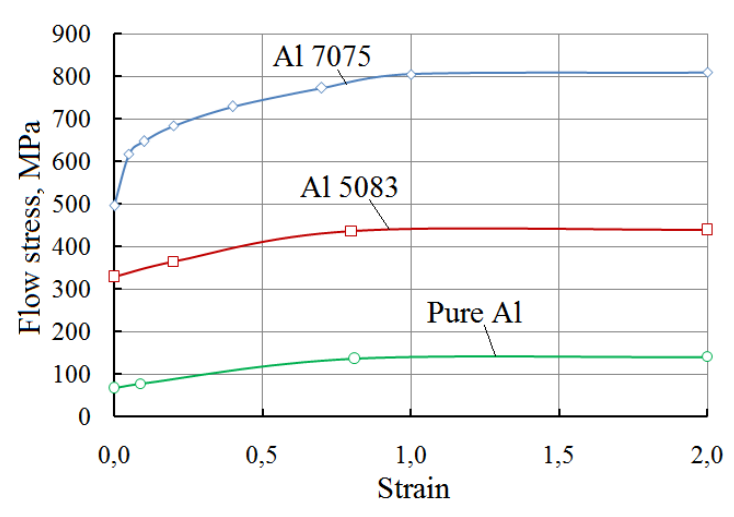

Figure 2. Stress-strain curves of $\mathrm{Al}$ alloys used in FEM simulations

Table 1. Properties of materials used in FEM simulation

\begin{tabular}{|l|c|c|}
\hline \multicolumn{1}{|c|}{ Properties } & $\begin{array}{c}\text { Pure Al, } \\
\text { Al 5083, Al 7075 }\end{array}$ & AISI D2 \\
\hline $\begin{array}{l}\text { Thermal conductivity } \mathrm{k}, \\
\mathrm{W} /(\mathrm{m} \times \mathrm{K})\end{array}$ & 180.2 & 50.71 \\
\hline Emissivity $\varepsilon$ & 0.05 & 0.7 \\
\hline Heat capacity C, $/(\mathrm{kg} \times \mathrm{K})$ & 901.1 & 485.4 \\
\hline Density $\rho, \mathrm{kg} / \mathrm{m}^{3}$ & 2700 & 7850 \\
\hline $\begin{array}{l}\text { Heat transfer coefficient } \mathrm{H} \\
\text { between rolls and sheet, } \\
\mathrm{W} /\left(\mathrm{m}^{2} \times \mathrm{K}\right)\end{array}$ & $2000 ; 11000 ; 20000$ \\
\hline $\begin{array}{l}\text { Heat transfer coefficient } \mathrm{h}_{\mathrm{c}} \\
\text { between rolls } / \text { sheet and air, } \mathrm{W} /\left(\mathrm{m}^{2} \times \mathrm{K}\right)\end{array}$ & \multicolumn{2}{|c|}{20} \\
\hline $\begin{array}{l}\text { Stefan-Boltzmann radiation } \\
\text { constant, } \mathrm{W} /\left(\mathrm{m}^{2} \times \mathrm{K}^{4}\right)\end{array}$ & $5.6703 \times 10^{-8}$ \\
\hline $\begin{array}{l}\text { Environment temperature } \\
\mathrm{T}_{\infty},{ }^{\circ} \mathrm{C}\end{array}$ & \multicolumn{2}{|c|}{20} \\
\hline
\end{tabular}

The simulations were carried out at three different angular speeds of the bottom roll: $1 ; 5 ; 10 \mathrm{rad} / \mathrm{s}$. It corresponded to $0.1 \mathrm{~m} / \mathrm{s}, \quad 0.5 \mathrm{~m} / \mathrm{s}$ and $1.0 \mathrm{~m} / \mathrm{s}$ of circumferential speed. Speed of the top roll was reduced by $10 ; 30 ; 50 \%$ during asymmetric rolling. Sheet with initial dimensions of $2.0 \times 20.0 \times 50.0 \mathrm{~mm}$ was used for all simulations. The number of initial brick elements was 14220 for the sheet. Rolls were meshed with 123035 tetrahedral elements. An automatic remeshing was used in all the simulations. The boundary conditions were set in order to constrain the symmetry plane of the rolls and sheet along the rolling direction. A Coulomb friction model was used between rolls and sheet:

$$
\mathrm{f}_{\mathrm{S}_{1}}=\mu \mathrm{p}
$$

where $f_{S_{1}}$ is the friction stress, $\mu$ is the friction coefficient, $\mathrm{p}$ is the interface pressure between two bodies.

The influence of the friction coefficient $(0.1 \ldots 0.4)$, rolling speed $(0.1 \ldots 1.0 \mathrm{~m} / \mathrm{s})$ and rolls speed ratio (up to $50 \%$ ) on the temperature field of asymmetrically rolled aluminium sheets were analysed.

\section{Simulation results and discussion}

The aluminium alloy sheets are heated by friction and plastic deformation work during symmetric and asymmetric cold rolling processes. Friction heat is generated on the interfaces and completely distributed between the sheet and rolls. Plastic work of deformation occurs with heat generation in the interior of the sheet. It is expected that the sheets could be heated differently during symmetric and asymmetric cold rolling processes. So the temperature change during symmetric and asymmetric rolling was analysed and compared. Fig. 2 shows the temperature change of the Al 7075 sheet during symmetric rolling where thickness reduction is $50 \%$, friction coefficient is 0.4 and heat transfer coefficient $\mathrm{H}=11000 \mathrm{~W} /\left(\mathrm{m}^{2} \times \mathrm{K}\right)$. With increasing the rolling speed from $0.1 \mathrm{~m} / \mathrm{s}$ to $1.0 \mathrm{~m} / \mathrm{s}$, the maximum temperature of rolled sheets is increased from $159{ }^{\circ} \mathrm{C}$ (Fig. 2, a) to $231^{\circ} \mathrm{C}$ (Fig. 2, b).
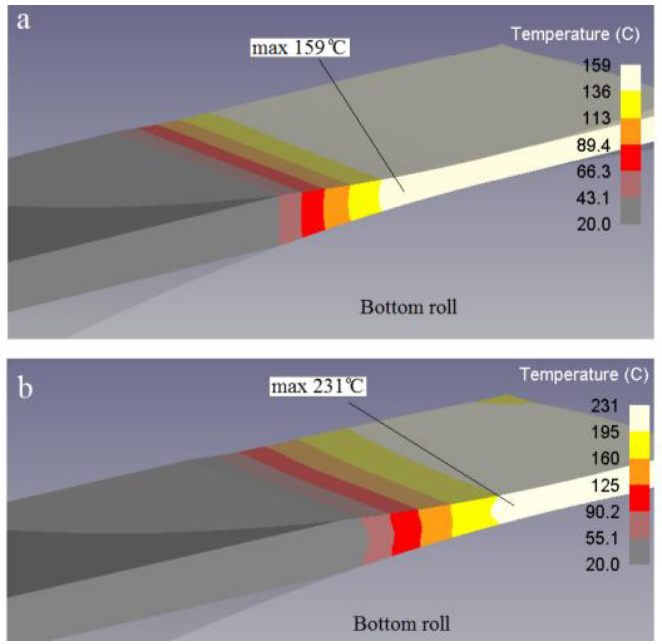

Figure 3. Temperature field in the deformation zone during symmetric rolling: a - rolling speed is $0.1 \mathrm{~m} / \mathrm{s} ; \mathrm{b}-1.0 \mathrm{~m} / \mathrm{s}$

Fig. 3 shows the temperature change of the $\mathrm{Al} 7075$ sheet during asymmetric rolling where heat transfer coefficient $\mathrm{H}=11000 \mathrm{~W} /\left(\mathrm{m}^{2} \times \mathrm{K}\right)$, thickness reduction is $50 \%$, rolls speed ratio is $50 \%$ and friction coefficient is 0.4 . It should be noted that the rolling speed is the most important factor that influences the temperature rise of $\mathrm{Al}$ sheets during asymmetric rolling. With increasing the rolling speed from $0.1 \mathrm{~m} / \mathrm{sec}$ to $1.0 \mathrm{~m} / \mathrm{s}$, the maximum temperature in rolled Al 7075 sheets increases from $217^{\circ} \mathrm{C}$ (Fig. 3, a) to $328^{\circ} \mathrm{C}$ (Fig. 3, b). So the temperature rise can be controlled through adjustment of the rolling speed.

Homogeneous temperature distribution through sheet thickness was obtained at the exit of deformation zone in all cases of asymmetric rolling. But temperature distribution along the width of the sheet was inhomogeneous (Fig. 3).

High shear strain through thickness of the sheet can be obtained only with a high value of friction coefficient. But it leads to temperature rise of the rolled aluminium sheets. Decreasing of the contact friction coefficient is beneficial to reduce the temperature in deformation zone 
(Fig. 4), but it also leads to significantly decreasing of the shear angle and shear strain during asymmetric rolling.
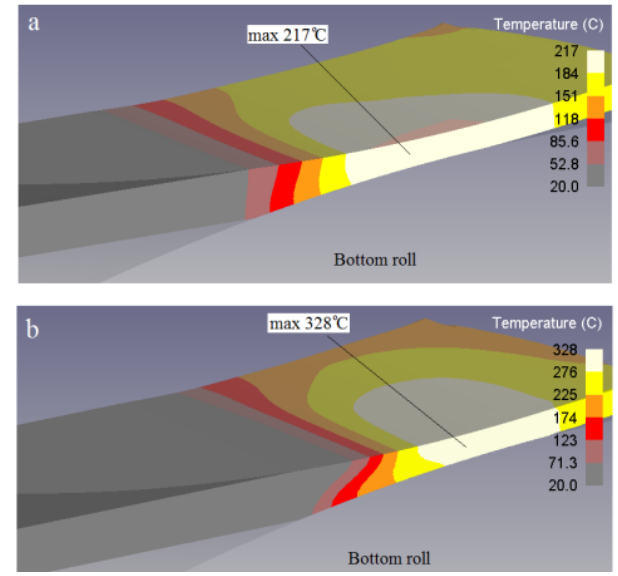

Figure 4. Temperature field in the deformation zone during asymmetric rolling: a - rolling speed is $0.1 \mathrm{~m} / \mathrm{s} ; \mathrm{b}-1.0 \mathrm{~m} / \mathrm{s}$
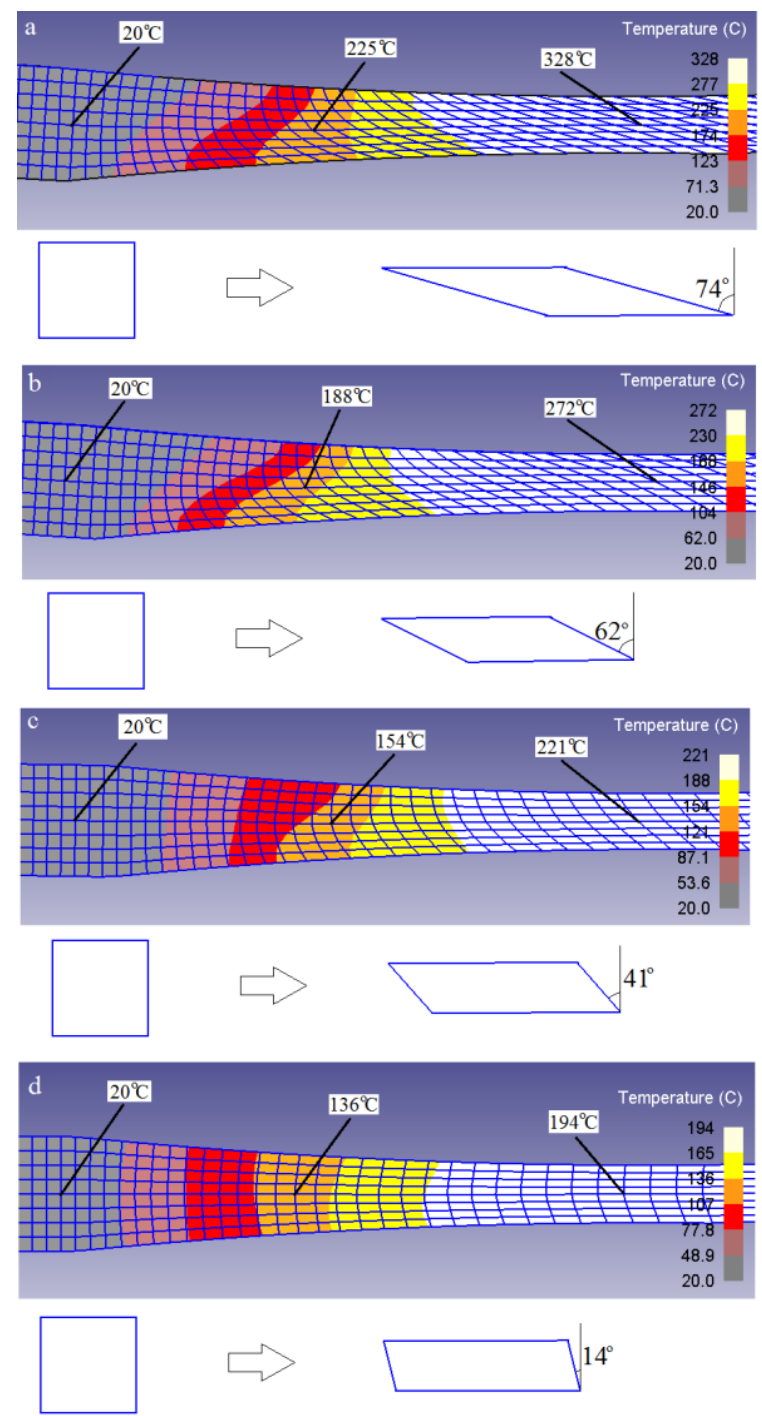

Figure 5. Temperature field and shear angle during asymmetric rolling with different friction coefficient $\mu=0.4$ (a); $\mu=0.3$ (b); $\mu=0.2$ (c); $\mu=0.1$ (d) (Al 7075, thickness reduction is $50 \%$, rolls speed ratio is $50 \%$; rolling speed is $1.0 \mathrm{~m} / \mathrm{s}$; heat transfer coefficient is $11000 \mathrm{~W} /\left(\mathrm{m}^{2} \times \mathrm{K}\right)$ in all calculation variants $)$.
Contact friction is one of the main factors that affect the shear strain during asymmetric rolling. High friction coefficient increases the opposite contact friction forces which operates in the deformation zone and it creates an additional shear strain. Decreasing of the friction coefficient leads to serious decrease of the effective strain (Fig. 5).
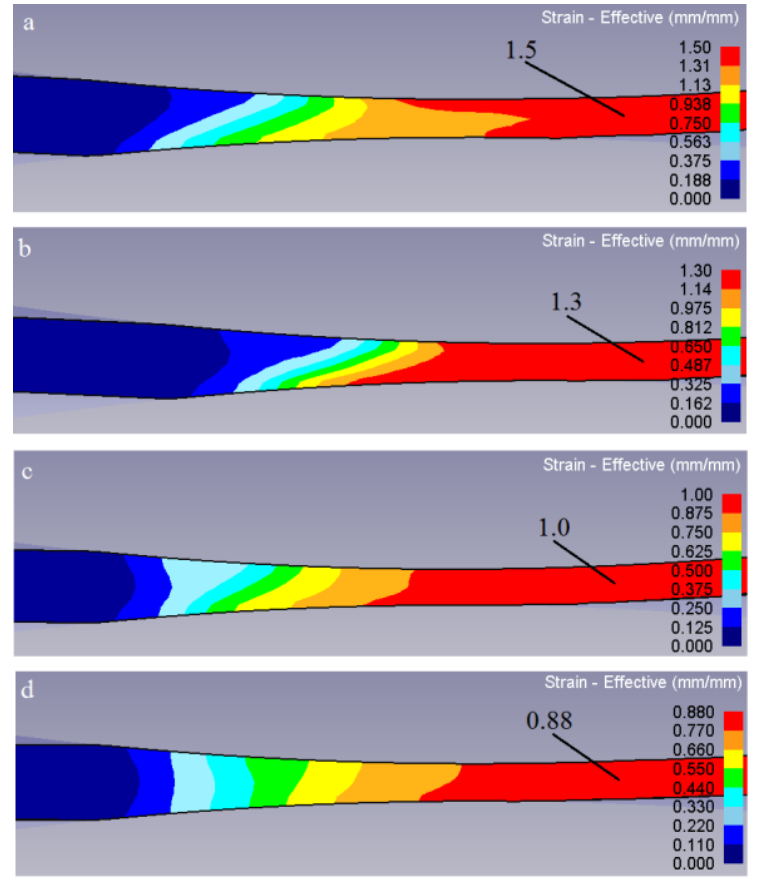

Figure 6. Effective strain during asymmetric rolling with different friction coefficient $\mu=0.4$ (a); $\mu=0.3$ (b); $\mu=0.2$ (c); $\mu=0.1$ (d) (Al 7075, thickness reduction is $50 \%$, rolls speed ratio is $50 \%$; rolling speed is $1.0 \mathrm{~m} / \mathrm{s}$; heat transfer coefficient is $11000 \mathrm{~W} /\left(\mathrm{m}^{2} \times \mathrm{K}\right)$ in all calculation variants $)$

Increasing the rolling speed leads to serious increase of the temperature in the deformation zone (Fig. 6). The friction heat is generated on the interfaces and it is distributed between the aluminium sheet and rolls. Increasing the rolling speed leads to decreasing of the contact time. Therefore heat is less intensive transferred to the rolls and to environment.

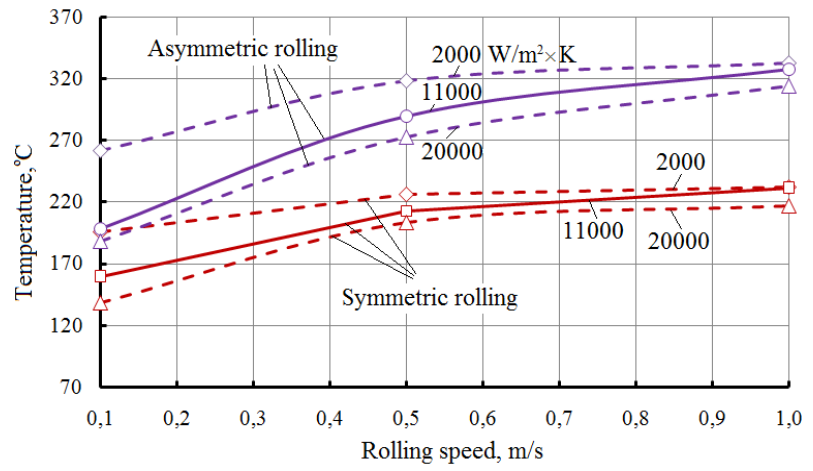

Figure 7. Interrelation of the temperature in the deformation zone and rolling speed during symmetric and asymmetric rolling of $\mathrm{Al} 7075$ with different heat transfer coefficient $\mathrm{H}$ between rolls and sheet (thickness reduction is $50 \%$, friction coefficient is 0.4 , rolls speed ratio is $50 \%$ for asymmetric rolling) 
Fig. 7 shows the interrelation of the temperature in the deformation zone and rolls speed ratio during rolling. With increasing the rolls speed ratio to $50 \%$, the temperature of rolled Al 7075 sheets is increased from $230{ }^{\circ} \mathrm{C}$ to $328{ }^{\circ} \mathrm{C}$ (for $\mathrm{H}=11000 \mathrm{~W} / \mathrm{m}^{2} \times \mathrm{K}$ ). It can be explained by more serious sliding velocity on the contact surfaces. As a result the friction heat is generated.

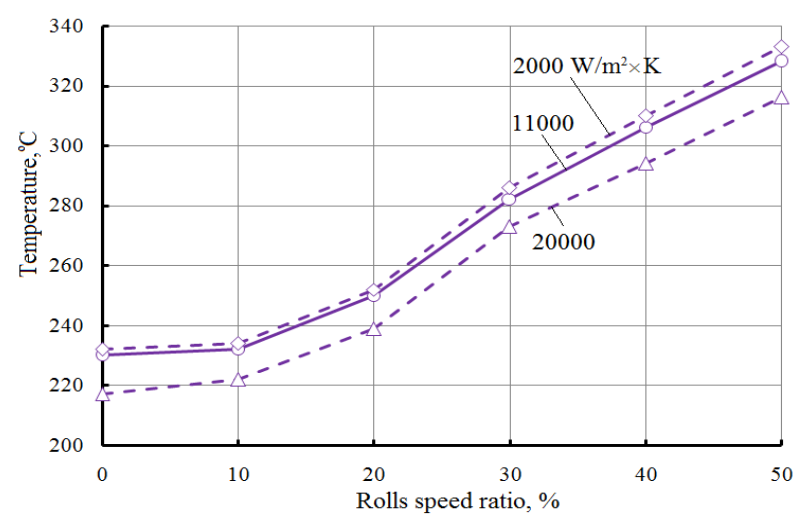

Figure 8. Interrelation of the temperature in the deformation zone and rolls speed ratio ( $\mathrm{Al} \mathrm{7075}$, thickness reduction is $50 \%$, friction coefficient is 0.4 , rolling speed is $1.0 \mathrm{~m} / \mathrm{s}$ )

Fig. 8 shows the interrelation of the sliding velocity and friction coefficient during symmetric rolling. Negative sliding velocity corresponds to backward slip zone. Positive sliding velocity corresponds to forward slip zone. Sliding velocity on the contact surfaces has an influence on temperature through frictional heat. On the one hand increasing contact friction coefficient leads to decrease of sliding in the backward slip zone. On the other hand increasing friction coefficient leads to increase of sliding in the forward slip zone. Although sliding in the backward slip zone is more serious.

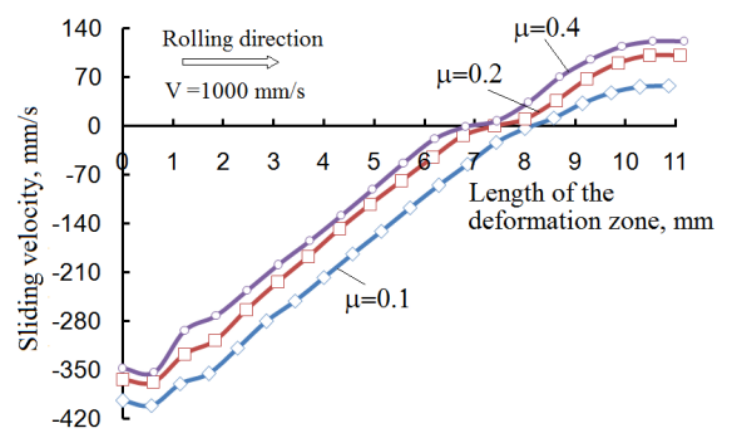

Figure 9. Sliding velocity on the contact surfaces during symmetric rolling with different friction coefficients (Al 7075, thickness reduction is $50 \%$, rolling speed is $1.0 \mathrm{~m} / \mathrm{s}$, heat transfer coefficient is $11000 \mathrm{~W} /\left(\mathrm{m}^{2} \times \mathrm{K}\right)$

Sliding velocity on the contact of the top roll during asymmetric rolling with different friction coefficients is shown in Fig. 9. High friction coefficient increases the sliding velocity in the forward slip zone.

Forward slip zone is absent on the contact with the bottom (fast) roll (Fig. 10). It corresponds to the cases when rolls speed ratio is equal to thickness reduction per pass. Increasing of the friction coefficient leads to decrease of the sliding velocity. As a result the friction heat is more serious on the contact with the top (slow) roll.

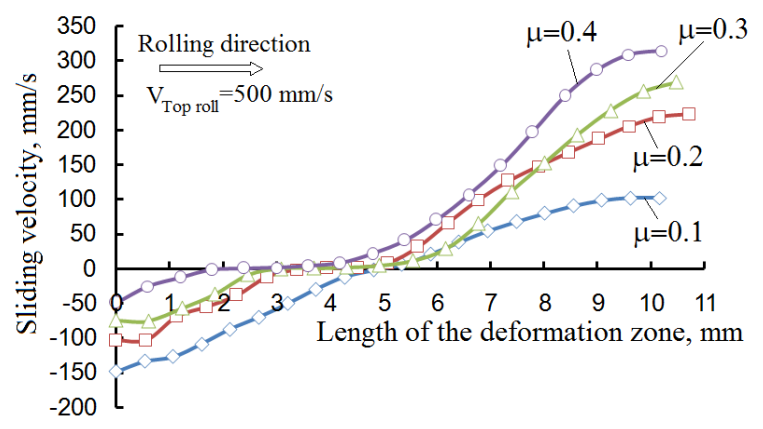

Figure 10. Sliding velocity on the contact of the top roll during asymmetric rolling with different friction coefficients (Al 7075, thickness reduction is $50 \%$, rolls speed ratio is $50 \%$, heat transfer coefficient is $11000 \mathrm{~W} /\left(\mathrm{m}^{2} \times \mathrm{K}\right)$

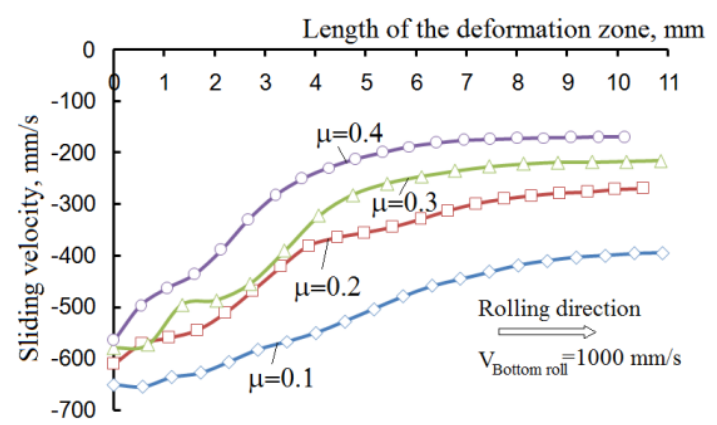

Figure 11. Sliding velocity on the contact of the bottom roll during asymmetric rolling with different friction coefficients (Al 7075, thickness reduction is $50 \%$, rolls speed ratio is $50 \%$, heat transfer coefficient is $11000 \mathrm{~W} /\left(\mathrm{m}^{2} \times \mathrm{K}\right)$

Fig. 11 shows the interrelation of the temperature in the deformation zone and friction coefficient during asymmetric rolling. Rise of temperature in deformation zone is significantly different during asymmetric rolling of pure aluminium and its alloys 7075, 5083. With increasing the friction coefficient from 0.1 to 0.4 , the temperature of rolled sheets is increased from $50{ }^{\circ} \mathrm{C}$ to $78{ }^{\circ} \mathrm{C}$ for pure aluminium, from $127{ }^{\circ} \mathrm{C}$ to $236{ }^{\circ} \mathrm{C}$ for $\mathrm{Al} 5083$ and from $194{ }^{\circ} \mathrm{C}$ to $328^{\circ} \mathrm{C}$ for $\mathrm{Al} 7075$ (for $\left.\mathrm{H}=11000 \mathrm{~W} / \mathrm{m}^{2} \times \mathrm{K}\right)$. It can be explained by more serious work of plastic deformation during asymmetric rolling of much stronger material.

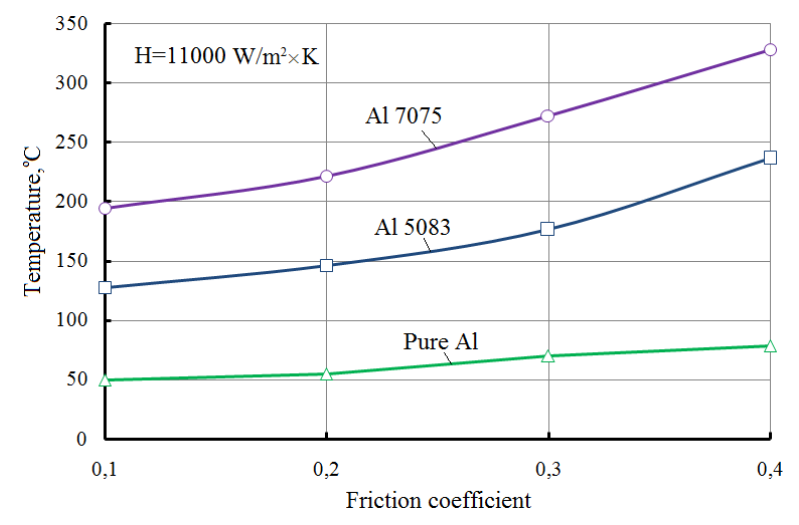

Figure 12. Interrelation of the temperature in the deformation zone and friction coefficient during asymmetric rolling of pure 
$\mathrm{Al}$ and alloys $\mathrm{Al} 7075, \mathrm{Al} 5083$ (thickness reduction is 50\%, rolling speed is $1.0 \mathrm{~m} / \mathrm{s}$, rolls speed ratio is $50 \%$ )

The microstructure of $\mathrm{Al}$ alloys is affected by the thermal field during asymmetric rolling. The temperature level of dynamic recovery and grain growth should be further studied in future.

\section{CONCLUSIONS}

The aluminium alloy sheets are heated by friction and plastic deformation work during asymmetric cold rolling. This paper presents the results of FEM simulation of the effect of contact friction, rolling speed and rolls speed ratio on the heating of aluminium sheets. Asymmetric rolling process leads to serious increase of the temperature in the deformation zone in comparison with conventional rolling. The temperature rise can be controlled through adjustment of the rolling speed.

The heat transfer analysis presented in this study can be used to optimize the asymmetric rolling process as SPD method to improve microstructure and mechanical properties of aluminium sheets. The temperature level of dynamic recovery and grain growth should be further studied in future.

\section{ACKNOWLEDGEMENTS}

The study was supported by a grant of the Russian Science Foundation (project No15-19-10030)

\section{REFERENCES}

1. I. Sabirov, M.Yu. Murashkin, R.Z.Valiev, Materials Science \& Engineering A. 560 (2013) 1-24

2. V.I. Elagin, Metal Science and Heat Treatment. 9 (2007) 3-11

3. R.K. Islamgaliev, et al., Materials Science and Engineering: A. 319-321 (2001) 877-881

4. Y. Estrin, A. Vinogradov, Acta Materialia. 61 (2013) 782-817

5. Q. Cui, K. Ohori, Materials Science and Technology. 16 (2000) 1095-1101

6. J. Jiang, Y. Ding, F. Zuo, A. Shan, Scripta Materialia. 60 (2009) 905-908

7. Loorentz, Young Gun Ko, Journal of Alloys and Compounds. 536S (2012) S122-S125

8. Loorentz, Y.G. Ko, Journal of Alloys and Compounds. 586 (2014) S205-S209

9. J.K. Lee, D.N. Lee, International Journal of Mechanical Sciences. 50 (2008) 869-887

10. K. Bobor, Z. Hegedus, J. Gubicza, I. Barkai, P. Pekker, G. Krallics, Periodica Polytechnica Mechanical Engineering. 56 (2012) 111-115

11. F. Zuo, J. Jiang, A. Shan, Transactions of Nonferrous Metals Society of China, 18 (2008) 774777

12. J.K. Lee, D.N. Lee, Key Engineering Materials. 340341 (2007) 619-626

13. A. Pesin, M. Chukin, A. Korchunov, D. Pustovoytov, Key Engineering Materials. 622-623 (2014) 912-918
14. A. Pesin, A. Korchunov, D. Pustovoytov, Key Engineering Materials. 685 (2016) 162-166

15. M. Sverdlik, A. Pesin, D. Pustovoytov, A. Perekhozhikh, Advanced Materials Research. 742 (2013) 476-481

16. Y.H. Ji, J.J. Park, Materials Science and Engineering: A. 499 (2009) 14-17

17. Y.H. Ji, J.J. Park, W.J. Kim, Materials Science and Engineering: A. 454-455 (2007) 570-574

18. W.J. Kim, B.G. Hwang, M.J. Lee, Y.B. Park, Journal of Alloys and Compounds. 509 (2011) 8510-8517

19. J.J. Park, Computational Materials Science. 100 (2015) 61-66

20. A. Pesin, D. Pustovoytov, Key Engineering Materials. 622-623 (2014) 929-935

21. O. Yevtushenko, Acta Mechanica et Automatica, 2 (2008) 99-102

22. W.R.D. Wilson, C.T. Chang, C.Y. Sa, Journal of Materials Shaping Technology, 6 (1989) 229-240

23. Modern Manufacturing Engineering, Edited by J. Paulo Davim, Springer International Publishing (2015)

24. Handbook of Workability and Process Design, Edited by George E. Dieter, Howard A. Kuhn, S. Lee Semiatin, ASM International (2003) 